\title{
(Dis)Embodied Air Travel Experiences: Disability, Discrimination and the Affect of a Discontinuous Air Travel Chain
}

\author{
Simon Darcy \\ University of Technology, Sydney, \\ Australia
}

\begin{abstract}
This article presents an investigation of the embodied air travel experiences of people with disability. The study was informed by human rights frameworks, social approaches to disability and critical tourism. The research design included a review of newspaper articles, human rights complaint cases, open-ended responses to a survey on the tourism experiences of people with disabilities and semistructured in-depth interviews. The findings revealed that the air travel practices routinely contravened disability discrimination legislation and identified a series of socially constructed constraints across the air travel chain from the preplanning of trips through to disembarking after a flight. What emerged from these experiences was that the embodied individuals became (dis)embodied at each stage of the air travel chain. The inequitable, inaccessible, undignified and dependent practices resulted in heightened anxiety, increased helplessness and, in some cases, humiliation to which they were not subjected in their everyday lives.
\end{abstract}
Keywords: air travel, travel chain, disability, embodiment, human rights, citizenship, lived
experience, social model
Keywords: air travel, travel chain, disability, embodiment, human rights, citizenship, lived
experience, social model

\begin{abstract}
The genesis of this article came from ongoing media coverage over the last two decades of the air travel experiences of people with disability (PwD) - a global phenomenon not restricted to western or eastern practices or the developed or developing world. Two recent examples from Europe (European Disability Forum, 2011) and New Zealand (The Dominion Post, 2011) identified that the issue is not just a case of service failure but one of disability discrimination. Disability discrimination occurs when PwD are treated less fairly than people without a disability before the law. The newspaper articles highlight the multidimensional outcome for the individuals involved - discriminatory practices had the effect of constraining their citizenship. The media examples link the theoretical developments in the study of disability, tourism and the growing body of knowledge on accessible tourism. The issue falls within the United Nations Convention On the Rights of Persons with Disabilities (CRPWD), which is underpinned by social approaches to disability (Kayess \& French, 2008). The article takes up the challenge posed by disability studies academics (Shakespeare \& Watson, 2001; Thomas, 2004) to incorporate a more complex understanding of embodiment than the cur-
\end{abstract}

\section{Correspondence}

Simon Darcy, Associate Professor, UTS Business School, University of

Technology, Sydney, P.0. Box 222 Lindfield NSW 2070, Australia.

E-mail: simon.darcy@uts.edu.au rent dichotomous social model understanding of impairment and disability (as discussed later). To this end, critical theory in tourism has also incorporated embodiment as core to its approach and it is argued that the social model of disability and critical tourism bodies of knowledge provide an opportunity to move beyond identifying constraints to seek transformative outcomes for tourists with disabilities (TwD).

To achieve this outcome, the article seeks to explore the 'essence' of air travel experiences for TwD. The exploration of the practices and experiences offers an opportunity to empower and emancipate air travel for PwD. As such, the lived experience of the TwD is the subject of the article, which examines the embodied outcomes of the air travel experiences. For this article, Osborne's (2000, p. 51) definition of 'embodiment' is used to describe the way in which the 'bodily bases of individuals' actions and interactions are socially structured; that is, embodiment is a social as well as natural process'. Buhalis and Darcy (2011) argue that embodiment for PwD is not a homogenous construct, as it includes mobility, hearing, vision, learning, sensitivities and mental health, among others. Within each of these distinct embodiments, the inclusion of PwD is further affected by their level of support needs - from individuals who are free and independent travellers through to those with very high support needs that require 24-hour one-on-one support to participate in tourism experiences. Supplementary to this understanding of disabled embodiments, people use 
a variety of assistive technology that is part of their embodied identity. The combination of these factors (impairment + level of support need + assistive technology + life experience) create their embodiment that interacts with interpersonal relationships, environments, the social attitudes they encounter which in turn affects their citizenship.

The article first outlines the connection between the United Nations (UN) human rights CRPWD, air travel and disability. Second, the article then reviews the foundation of social model approaches, before reviewing critiques that call for a greater understanding of an individual's embodiment within these approaches. Third, the article extends this understanding of embodiment through critical theory in tourism. The research design is then presented followed by insights into the essence of the embodied air travel experience.

\section{Literature}

The United Nations (2006) CRPWD is regarded as a mechanism to eradicate the barriers faced by PwD to allow them full citizenship. Apart from the general principles of nondiscrimination and equal treatment before the law, Article 3 outlines the principles underlying the CRPWD, which include dignity, independence, participation, respect, disability as part of human diversity, equality of opportunity, gender equity and the rights of children. The general principles are reinforced by an underlying social model approach to disability, where the experiences of PwD are central to this understanding and where the CRPWD places the responsibility on governments and businesses to identify and eliminate barriers to participation (Kayess \& French, 2008). With respect to tourism, Articles 9 and 30 identify access to transportation and tourism as rights of citizenship. Both these Articles have significant implications for tourism providers but, more importantly, for disability citizenship in the tourism context.

The importance of including transportation and tourism as part of the CRPWD can be found in the multitude of studies investigating disability and tourism that have all identified air travel as a constraint for TwD (Daniels, Drogin Rodgers, \& Wiggins, 2005; Darcy, 1998; Turco, Stumbo, \& Garncarz, 1998). Examples of these constraints at their most disruptive include the refusal to allow people with mobility, vision or cognitive disabilities the right to fly. The reasons for the refusal to fly include procedural elements not having been completed to the satisfaction of the airline, no assistance provided for the person's access needs, equipment or oxygen unable to be transported by the airline and refusal to allow assistance animals to accompany people with vision impairment. Once a person has permission to fly, there are a series of infrastructure barriers, constraints and service failures experienced by TwD. This article will investigate the air travel experiences of TwD and embodied nature of these experiences.

Air travel has been democratised through low-cost carriers within and between national boundaries, transforming what had been regarded as cost-exclusionary for many (Doganis, 2005). Yet, while air travel has been a positive transformative mode of travel for many, there are many instances where air travel has had other transformative outcomes for
TwD. A great deal of air travel policy has been released by the national government agencies responsible for regulating domestic and international carriers (e.g., United Kingdom Department of Transport, 2003). Despite these efforts, newspaper databases (1995-2010) revealed hundreds of articles worldwide outlining the ongoing constraints that TwD encounter with air travel. An international indicator of the seriousness of the issues facing TwD was that in 2009 the United States (US) airline regulators introduced an amendment to the Air Carrier Act 1986 requiring all US and foreign air carriers to abide by US nondiscrimination laws for TwD in air travel, or lose their entitlement to fly to the US (U.S. Department of Transportation, 2009). The significance of this amendment and the duty that this has placed on foreign carriers with bilateral agreements with the US is both significant and much more stringent than most other national legislation and regulations. Following this brief introduction, the theoretical background on which the article is based is now explored.

Historically, research about PwD has been framed by those 'studying' disability, namely the medical and therapeutic professions (Barnes \& Mercer, 2010). This perspective has been referred to as the medical model of disability, which defines disability as a problem of the individual stemming from their 'deficits' (Oliver, 1996). The resultant dominant discourse views disability as a product of the 'abnormal body' rather than seeing a person's impairment as part of human diversity (United Nations, 2006; World Health Organization, 2001). The development of social approaches to disability over the last three decades has reconceptualised disability from being a 'personal tragedy' to a complex form of social oppression. A social approach recognises that it is not the person's impairment that is disabling but the environment and hostile social attitudes. These defining elements of the social model have been embedded within the CRPWD guiding principles. Yet, disability studies theorists have suggested that the dichotomy established in the social model between impairment and disability is more than just the disabling environmental and attitudinal foci. This article takes up this challenge by examining the importance of understanding the 'embodied ontology'; the nature of being of the bodily senses as affected by the structural context (Shakespeare \& Watson, 2001). Disability studies have begun to examine the 'nature of being' in a rehabilitative context, where an individual who is disabled through traumatic injury undergoes a process of re-embodiment as they learn to interact with enabling environments in their homes and localities, their assistive technology, negotiate the interpersonal attitudes around them and establish their new embodiment to become en-wheeled (Papadimitriou, 2008). In a tourism context, there is a complex interplay of impairment, disability and environment (Darcy, 2010; Packer, McKercher, \& Yau, 2007), where the characteristics of the individual must always be considered within the nature of customer-service relations. Using a systems approach to tourism (Leiper, 2003), one can imagine how this complex interplay needs to be negotiated when the individual travels from the tourist-generating region, where they interact with their day-to-day enabling environments, attitudes and assistive technologies, to the tourist-destination 
region, where any one or all of the may be absent or disrupted during the travel chain. The 'travel chain' 'refers to all elements that make up a journey, from starting point to destination - including the pedestrian access, the vehicles, and the transfer points. If any link is inaccessible, the entire trip becomes difficult' (World Health Organization \& World Bank, 2011, p. 179). This is more problematic when travelling away from their normal place of residence.

The social model informs this research by providing an understanding that socially constructed relationships are developed from three elements: (a) the lived experiences of TwD, (b) identifying disability as the combination of impairment (intrapersonal) and socially constructed barriers (interpersonal, environment and attitudes) and (c) a conceptual clarification that transforms disabling environments to enabling environments through practices that remove structural and attitudinal barriers (Swain, Finkelstein, French, \& Oliver, 2004). The social approach has been shown as an appropriate framework from which to analyse the relative inclusion of PwD in citizenship (Swain et al., 2004). In a leisure context, social approaches to disability can be fundamental to identifying constraints, informing industry practice and seeking to empower TwD to forge their own identity (Tregaskis, 2003).

Surprisingly few studies have used a social model conceptualisation to understand disability and tourism. Darcy (2002) examined the tourism patterns of people with physical disabilities with high support needs, differentiating the group based on whether people required an attendant to travel with them, the type of mobility aid and the underlying impairment. Apart from the structural constraints identified in the tourism environment, he concluded that there were significant social policy issues that need to be addressed. Shaw and Coles (2004) placed the legislative requirements in context of the social model through six person-centred case studies, where they recognised that physical access is only one part of a broader understanding; one also needs to consider economic constraints and wider social considerations. McKercher, Packer, Yau and Lam (2003) discuss the social model in the context of the biopsychosocial approach, where the interactions between impairment, environment and industry are complex social constructions. Daruwalla and Darcy (2005) undertook research examining the effectiveness of disability awareness training on challenging attitudinal barriers within the tourism industry. Their findings show disability-awareness training to be an effective mechanism for changing attitudes when coupled with direct contact with PwD and ongoing workplace reinforcement. While identifying the disabling nature of the socially constructed barriers, no attention is given to embodiment or the tourist experience.

Within critical approaches to tourism, there is a growing body of literature on the importance of understanding embodiment within the travel experience. Over the last 20 years, critical theory in tourism has developed as an approach that seeks social transformation. Rather than simply identifying problems with social situations, critical theory seeks to address the problems with a clearly identified way forward. As Horkheimer explained, critical theory is based on the premise that:

\begin{abstract}
... it must explain what is wrong with current social reality, identify the actors to change it, and provide both clear norms for criticism and achievable practical goals for social transformation. Any truly critical theory of society... "has as its object human beings as producers of their own historical form of life" (Horkheimer, 1993, p. 21, in Bohman, 2005, para. 3).
\end{abstract}

Tourism as an agent for transformation has lagged behind leisure studies, where inequity, nonparticipation and strategies for inclusion have always been an important part of scholarship (Darcy \& Taylor, 2009). Tourism, by its market nature, has always valued neoliberal principles of profit and yield, where the socially disadvantaged have rarely entered mainstream discourse. Wilson, Harris and Small (2008, p. 16) reinforce that critical theory is not simply critical of past grand tourism theories in the same way that postmodernist paradigms have been critical, but seeks practical outcomes for inequalities where they exist and emphasise the important philosophical difference underpinning such research:

While ontological, epistemological and methodological differences may exist, those employing a critical approach would generally be concerned with resisting positivist modes of enquiry, unmasking power relations, seeking emancipation, addressing inequalities or calling for change or action within the field they are exploring.

Within this paradigm, there has been a growing body of literature examining the role of embodiment within gendered representations of tourism examining not only how tourism represents itself but how industry practice welcomes some bodies over others (Pritchard, Morgan, Ateljevic, \& Harris, 2007; Small, Harris, \& McIntosh, 2008; Waitt \& Markwell, 2006). The bodies that are welcomed are rich, young, White, nondisabled, heterosexual, slim and 'attractive'. A more nuanced understanding of disability has been developed by Buhalis and Darcy (2011) who argue for a more complex consideration of disability from the constituent dimensions (e.g., mobility, vision, hearing and others). They identify that an individual's embodiment is affected by their level of support needs and assistive technology, which combine to affect embodied variances. More recent conceptualisations of accessible tourism examine the embodied experiences of tourists with mobility and vision impairment (Small \& Darcy, 2011), mental health (Fullagar, 2011) and blind/vision impairment (Richards, Pritchard, \& Morgan, 2010) and the outcomes that arise from tourism experiences. These contributions demonstrate a need to understand disability beyond the structural elements identified in the social model. Instead, they suggest that accessible tourism experiences need to incorporate bodily sensory experiences 'beyond the visual gaze' (hearing, taste, feel and smell) (Small, Darcy, \& Packer, 2012).

Cole and Morgan (2010, p. xv), reaffirm that the transformational nature of critical approaches to tourism is required to redress inequality. However, they suggest further progression through the development of 'hopeful tourism', where:

tourism is part of wider social, economic, political, ecological and cultural processes ... in order to expose the relationships between tourism and inequality; more than this, however, its contributors also review international examples of socially responsible tourism to provide a stock 
of good practice cases for tourism students, educators, practitioners and activists. (Cole \& Morgan, 2010, p. xv)

In contributing empirical work to develop this understanding, Richards, Pritchard and Morgan (2010) examined the experiences of tourists who are blind or have vision impairments within the tourism context. Their research discusses the experiences of the group under three underlying themes; embodied tourism encounters, inhospitable tourism spaces and navigating through the environments. From an embodied perspective, their work highlights how the tourism industry needs to understand embodied experiences more than just through a visual lens, where experiences need to incorporate the other senses (hearing, taste, feel and smell) to adequately provide tourism experiences for the group, to understand how to construct these experiences and to allow independent wayfinding.

Against this background, this study takes up the challenge to extend the social model approaches with the call for a greater embodied understanding within the lived experience. Central to this is the call to move beyond the dichotomy of impairment and disability definitions identified in the social model and to recognise the importance of an individual's embodiment as the subject of the lived experience (Papadimitriou, 2008). In doing so, the principles of the CRPWD of accessibility, independence, equity and dignity that underlies social and embodied approaches to disability are promoted (Barnes \& Mercer, 2010; United Nations, 2006).

\section{An Embodied Understanding of Air Travel Experiences}

The article seeks to answer the following research questions:

- What are the air travel experiences of TwD?

- What effect do these experiences have on their embodied state?

- Can airline practices be improved from understanding these embodied experiences?

To investigate these questions, the research design used a mixed-method interpretative approach to understand the phenomenology of TwD experiences. The research design was guided by the human rights framework, social approaches to disability and embodied knowledge suggested by disability studies and critical tourism.

\section{Research Design and Analysis}

To gain an understanding of the essence of the air travel experience, this study analysed data from previous studies on the tourism experiences of PwD that included air travel but had not previously been published. The studies included data collected via open-ended survey responses $(n=2600)$ and in-depth interviews $(n=19)$ (Darcy, 2004, 2010), an updated dataset of complaints cases $(n=673)$ brought under the Australian Disability Discrimination Act of which 41 are air-travel-related (Darcy \& Taylor, 2009) and relevant media accounts of air travel experiences of TwD. The detailed methodologies for each of these studies are not presented in this article but can be read in conjunction with those individual articles.

For this study, the analysis involved a continual comparison of the qualitative data (Glaser \& Strauss, 1967) and the underlying principles of the CRPWD (Barnes \& Mercer, 2010; United Nations, 2006). This analysis was extended to examine the embodied nature of air travel experiences as framed by the disability studies and critical tourism literature. With regards to the CRPWD, data were analysed as to whether the practices promoted citizenship through accessible, independent, dignified and equitable means or disempowered citizenship through creating inaccessible, dependent, undignified and inequitable citizenship (Barnes \& Mercer, 2010; United Nations, 2006). These concepts are complex, interdependent and overlapping and require a high degree of technical understanding. The researcher's personal experience of disability assists in an understanding, interpreting and analysing the data. The researcher has 25 years of lived experience with disability, is a member of multiple cross-disability advocacy organisations that routinely work with all disability types and support needs. $\mathrm{He}$ is qualified professionally as an environmental planner and access auditor. To provide further insights, the qualitative data was read to understand the essence of the air travel experience through a phenomenological approach (Holstein \& Gubrium, 1994). This moved beyond the method of identifying constraints that has dominated the analysis of TwD experiences and sought to understand the 'nature of being', the tourists' feelings and how these affected their embodiment (Barnes \& Mercer, 2010; Papadimitriou, 2008). Given the relatively underresearched status of embodied disability research, this study hopes to contribute a new dimension to our embodied understanding of accessible tourism and air travel specifically.

\section{Findings}

The overwhelming finding from the data collected was that there were multiple practices that contravened the accessibility of the air travel chain for TwD and were deemed discriminatory based on disability under the international and national frameworks. The complaint case data identified some 26 air travel environments, practices and attitudes that were deemed discriminatory for people with mobility, vision, hearing, cognitive and other disabilities. The nature of discrimination varies for individuals, depending on their impairment. People with vision impairment who use guide dogs are confronted with inappropriate service attitudes as to their right of access and the built environment issues related to independent wayfinding. People with hearing impairments' requirements for alternative information provision are consistently ignored. People with fatigue-related conditions that require oxygen are faced with inconsistent procedural frameworks together with discriminatory practices to exclude their equipment needs. While this data provides an insight into the nature of discriminatory access considerations it does not provide an understanding of the essence of experience or the effect that the practices have on the nature of being of the TwD. The next section uses the complaint cases, Federal Court actions and in-depth interviews with TwD and newspaper accounts to explore 
Table 1

Stages of Travel and Quotes

\begin{tabular}{|c|c|}
\hline Stages & Quotes \\
\hline A. Pretravel planning & $\begin{array}{l}\text { 1. 'It's a form of segregation that creates all sorts of problems when you're trying book with your friends or work colleagues. You } \\
\text { secure the fares but then they (the airlines) can bump you for any number of reasons'. (Interviewee) }\end{array}$ \\
\hline B. Boarding and disembarking & $\begin{array}{l}\text { 2. 'You get stuck in those bloody, shitty airport wheelchairs and you can't go anywhere. It might be there for half-an-hour, and if } \\
\text { you're stuck without access to your own chair, in one of those aisle chairs that you can't actually push around and go to the } \\
\text { bathroom or get yourself a feed... it's a loss of independence... I'm self-catheterised, so if you don't get to the bathroom, you } \\
\text { piss your pants. It's not the best way to be.' (Interviewee) } \\
\text { 3. 'As he said to me, he is just one of the baggage staff that they asked to help out because they were short of staff. It showed, as } \\
\text { I thought he was going to throw me into the other seat. He was strong but it's not about strength, it's about technique'. } \\
\text { (Interviewee) }\end{array}$ \\
\hline C. Seat allocation & $\begin{array}{l}\text { 4. 'My very first flight they put me right down the very back. I had to squeeze all the way down the aisle to the back seat. Because } \\
\text { I can't transfer myself, I have to be lifted over the armrest by the carer and the porters at the airport ... one gets on the legs, and } \\
\text { the other on the back and transfers me across'. (Interviewee) }\end{array}$ \\
\hline D. Onboard personal care issues & $\begin{array}{l}\text { 5. 'On previous overseas trips I have found getting to the toilet extremely difficult because of the tiny size of plane toilets. It's put } \\
\text { me right off travelling by plane'. (Interviewee) } \\
6 \text {. 'I don't think that I could get into a toilet in a plane... I have got a normal bladder function but I tend to hold on for a very long } \\
\text { time' (Interviewee) }\end{array}$ \\
\hline F. Customer service & $\begin{array}{l}\text { 8. 'I found the airline was really quite rude, in that (wife's name withheld) and I went to get on the plane and he yelled down the } \\
\text { corridor, "I've got a couple of carry-ons here" ... That whole bad attitude to the customers' rights'. (Interviewee) } \\
\text { 9. 'I have to say that I could find no fault at all with the treatment and the facilities provided by [airline name withheld] from the } \\
\text { moment I checked in at the airport in Sydney. In the past, I had gone on board planes where my brother had actually had to lift me } \\
\text { on board international flights because the crew wouldn't do it. So, it was such an amazement to me that seven years later the } \\
\text { crew couldn't do enough for you and provided me with anything that I needed'. (Interviewee) }\end{array}$ \\
\hline
\end{tabular}

the essence of the experiences of these discriminatory practices for people with mobility disabilities.

Stages of the Air Travel Chain. From the complaint cases and interviews it was apparent that the experience of air travel that had an impact on the individual's embodiment could broadly be analysed through the stages of the air travel process. Table 1 presents an overview of the stages together with a representative quote from the interviews. Each of the stages is now reviewed with the experiences outlined.

\section{Pretravel Planning}

In the pretravel planning stage, the online or traditional flight booking systems presented a different experience for the nondisabled and TwD. Once a TwD has booked their airfare via any means (internet, travel agent or packaged travel), they are required by carriers to make phone contact to ensure that the carrier is able to honour the ticket due to the access considerations. As one of the interviewees stated in Table 1 Quote 1, this equated to a segregated system for $\mathrm{TwD}$. Yet, rather than the telephone contact being procedural, some spoke about being 'interrogated' as to their health and independence status. What was particularly disconcerting for the interviewees was that the customer service people were asking questions outside the scope of the booking procedure to matters of medical privacy.

The booking issues became more critical when the independent travel criteria was introduced that required people who needed assistance with safety procedures to travel with a carer. For many like Paralympian Paul Nunnari, who instigated a Federal Court action (having travelled independently for over a decade) this was an outrageous notion. The Federal Court action brought about a policy change that 'require carers to accompany those weighing more than 130 kilograms' (Pelly, 2006). Once the flight has been booked, an individual can still be refused the right to board based on an airline staff member's perception of the person's relative independence. A Federal Court action was instigated after a man was refused the right to fly by check-in staff on a return flight after he had travelled with the same airline in the morning (Public Interest Advocacy Centre, 2007). The check-in staff did not believe the passenger met the independent travel criteria and refused him the right to fly unless he was accompanied by an attendant. This situation took place at the customer service counter in front of other passengers. The passenger, who had travelled for many years independently, had his independence challenged together with his dignity in a public place. The other consideration of having an attendant is that, 'the cost of paying for an attendant is just prohibitive' (Interviewee); the more complex the travel chain, the more the issue is compounded.

Another limitation to air travel is the number of power wheelchairs allowed per flight on narrow-bodied jets (e.g., a 737). This is explained by the airlines in question as a design issue with the aircraft. In one case, this led to the forced separation of husband and wife, who were both power wheelchair users, by putting them onto different flights to the same destination. 'I was devastated - we always travelled together, as any couple would' (Interviewee). The complication of this situation is that this same couple travel with an attendant and now must travel with two attendants, one for each flight. Air travel to any conference or major event where the theme attracts delegates who are wheelchair users has also been found to be problematic.

Exceptions to these procedures are made by airlines for elite sportspeople travelling to team meets where they travel in groups of up to 100 . As private citizens not travelling as part of an elite sport team they are subjected to different 
rules by the same carrier. As a member of an elite sports team they have a continuous air travel chain, but as private citizens they have a segregated and discontinuous air travel chain experience. This has led to complaint cases and Federal Court actions, as outlined by the Paul Nunnari case earlier. This regulation affects not just the individuals involved but their significant others and families. After encountering barriers at flight booking and check-in, TwD then need to negotiate boarding and disembarking barriers.

\section{Boarding and Disembarking}

Aircraft are not independently accessible for people with mobility disabilities. The method of boarding and disembarking from the aircraft has a number of breaks to the travel chain. Due to the narrow aisles of aircraft, which do not accommodate a standard wheelchair, TwD must be transferred from their wheelchair onto an aisle chair before boarding. The aisle chairs are significantly smaller and narrower than a standard wheelchair, lack the means of self-propulsion and are not comfortable. As indicated in Table 1 Quote 2, this has serious implications for independence and dignity of the personal care of TwD. The importance of staying in one's own wheelchair for as long as possible cannot be overstated. Yet, transfer to the aisle chair before boarding is only the beginning of what many TwD described as a harrowing process. This involves more than discomfort; it can directly affect a sense of self; ' $M y$ husband's self-esteem plummets as we make our way through crowds waiting to board' (Interviewee).

The boarding and disembarking process involves what TwD describe as the first on, last off syndrome. TwD are required to board aircraft as much as 45 minutes before the nondisabled. This is due to the confined nature of the aisles, the use of the aisle chair and the need to transfer people from the aisle chair to the aircraft seat. The practice has the advantage of maintaining TwD's dignity as well as privacy from the curiosity of other passengers given that the transfer process from aisle chair to aircraft seat can involve readjustment of clothing and seating position. At times, however, the procedures for early boarding break down and TwD are boarded after the nondisabled. This creates a spectacle that one interviewee likened to 'being a freak in a circus', where they felt that everybody was staring at them. After the aircraft has landed, TwD only disembark after other passengers. The length of time to disembark is dependent on the number of porters available and the number of people requiring assisted disembarking. This results in TwD spending a minimum of an hour extra on an aircraft when the procedures go smoothly - and significantly longer when the procedures break down. One interviewee identified a three-hour wait.

Most major Australian airports employ porters to assist TwD and frail-aged to board and disembark from aircraft. In regional areas, this role falls to baggage handlers, cleaners or anyone else who is available and, hence, the level of expertise and training of different staff assisting TwD can vary tremendously. For example, Qantas introduced the Eagle lifter, which is an automated hoist transfer system that requires significant training for use. The outcome of this training was that interviewees have commented positively as to their air travel experiences with porters but some reported being humiliated when lifted in a swing hoist 'like a sack of potatoes' (Paine, 2005, p. xx). On the occasions where there is a breakdown in the procedures and training, the complaint cases and interviews identified issues with those assisting where inappropriate language was used or there were significant issues with manual handling procedures or other issues arose as identified in Table 1 Quote 3. These types of experiences create a sense of helplessness that most TwD have had to overcome through their adjustments to a disabling society. When these situations arise, it creates a sense of loss. For some, they may never fly again. For others, their future travel choices are restricted to modes of transport where their independence and dignity can be maintained. International air safety regulations also contribute to a heightened state of anxiety and helplessness: 'They don't make you feel very good when they say to you, "in the case of an emergency you are last out of the plane"!' (Interviewee).

\section{Seat Allocation}

While seat allocation is a contested issue for the nondisabled, for TwD the seat allocation can be particularly problematic for wheelchair users, as only certain rows of seats have armrests that flip up to allow for unhindered transfer from the aisle chair to the seat. Without this, the porters must lift the person over the arm of the chair. This can cause injury to the person and presents an occupational health and safety issue for porters. A number of the interviewees check and double-check booking details to the point of being compulsive. Yet, as they describe, this necessary behaviour is an indicator of their heightened anxiety due to their past poor experiences with seat allocation, as indicated by Table 1 Quote 4 . They require constant reassurance that the booking procedures have been correctly recorded; nevertheless, they frequently find a misallocation of seats on boarding the aircraft.

Many TwD expressed the desire to improve aircraft design, 'I think, for a start, the provision to stay in your own wheelchair within an aircraft would be brilliant' (Interviewee). With this provision they would not have to be separated from what they regard as part of their body, their wheelchair. While international air regulations are unlikely to allow TwD to travel in their wheelchairs, the requirement for all aircraft seats to have flip-up arms is sensible. This would alleviate the anxiety experienced when seeking assurance about the allocation of seat rows. Similarly, it was suggested that TwD could be allocated the bulkhead seating that has extra leg space. However, TwD are specifically excluded from these seats because they double as emergency exits and it is argued that TwD pose a risk of blocking these areas during an emergency.

\section{Personal Care Issues and Onboard Toilets}

Once the correct seat has been located, the arms raised and the porters ready to transfer, there are other considerations for personal comfort of TwD. For example, slide boards or slide sheets are positioned for transfer, therapeutic pressure-reducing seating cushions are placed on the 
airline seat and a chest harness is used in addition to airline seatbelts. To the nondisabled, these procedures may seem unusual but to a person with reduced mobility these are essential for posture and to protect skin against pressure. Air travel also presents a series of health issues for the nondisabled that have been highlighted by the publicity about deep-vein thrombosis. For TwD, any health issues need to be managed along with the inherent health issues arising from air travel. The problems associated with their loss of mobility are expressed by the following: ' . . twenty-four hours in a plane is not good for you, I get swollen ankles and stuff like that'. For another, the effects of rheumatoid arthritis make travelling an uncomfortable experience that is exacerbated by poor seating allocation, ' ... when I am taken on board, I am placed in the middle aisle again... with no leg room... with a leg that couldn't bend, I had nowhere to put my leg' (Interviewee).

From a personal health perspective, being able to maintain hydration also requires access to toilets. Yet access is nonexistent, as one interviewee laments: 'planes should have toilets that are wheelchair-accessible, both within Australia and overseas flights!' (Interviewee). Even with the newer aircraft design that offers an 'accessible' toilet, it is so far below the required access standards to be effectively unusable even for TwD with only moderate support needs. As another interviewee notes, 'On previous overseas trips I have found getting to the toilet extremely difficult because of the tiny size of plane toilets. It's put me right off travelling by plane' (Interviewee). For TwD with higher support needs, the use of the toilet requires cabin staff to provide the onboard aisle chair on the limited number of planes that have 'accessible' toilets. The person then has to be transferred by the cabin crew from the aircraft seat to the aisle chair. The aisle chair then has to be moved from the seating location into the accessible cubicle. Yet, even where accessible cubicles are provided, instances have arisen where the aisle chair has not been aboard and the person had to be carried to the toilet, which led to embarrassment and physical discomfort as outlined in one complaint case.

If there are no accessible toilets or the in-flight aisle chair cannot be used, TwD deal with continence management in different ways. It is a complex issue involving the mobility of the individual and their continence regime. Some TwD live within this constraint by not drinking and effectively dehydrating themselves during travel, as Table 1 Quote 5 demonstrates. Air travel is dehydrating generally and without fluid intake TwD risk more significant dehydration and other side effects (Rous \& Ward, 1997). This acts as a constraint on destination choice based on flight duration. For some, this has meant that 'flights we catch are only about an hour long so I do not have to access them (toilets)' (Interviewee). Other TwD cannot live with these restrictions and fly in fear of not being able to get to the toilet on aircraft, which creates a great deal of angst or they choose not to fly at all.

\section{Equipment Handling/Damage}

As Table 1 Quote 7 identifies, when undertaking air travel TwD take their equipment with them if they cannot hire equipment at the destination. Apart from the logistical con- siderations, some TwD reported ground staff reacting in less than a professional manner. For two married interviewees this involved the following issues: 'the airports generally freak out when we get there as we have a hoist, a commode, two portable ramps, both chairs and back pillows'. In other cases, there have been procedural issues about booking flights with extra equipment. This has led to complaint cases about oxygen for people with respiratory impairments and power wheelchair batteries. Quite literally, the people were separated from their bodily functioning. Both cases involved a misunderstanding by ground crew as to the procedures to accommodate these inclusions. The resolution of these complaint cases involved changes in booking policy and procedures to avoid undue delays or refusal of entry onto flights (Australian Human Rights Commission [AHRC], 2006). The equipment issue also relates to the secure stowing of wheelchairs once a person has been transferred onto an aisle chair. As one interviewee explains, he has a procedure for ensuring a safer passage in the luggage hold for his wheelchair by disassembling the chair and taking the joystick control on board, as 'that is the most vulnerable part of the chair...' (Interviewee).

Equipment damage is a major issue and if damage occurs to the only wheelchair on the way to a destination the damage can end the holiday experience. Some TwD reported being unable to continue their trip as replacement equipment was not available at the destination. Further, airlines have a limit of $\$ 1,600$ on damaged luggage and unless TwD have specifically taken out insurance on higherpriced equipment they are only covered for this limited amount. Most power wheelchairs cost in excess of $\$ 10,000$ and damage can easily exceed this limit. The other associated issue is lost equipment. Apart from the inconvenience, these losses can have a serious impact on the individual's embodiment where their independence and dignity is lost for the duration of the trip. In the case of a Tasmanian paraplegic whose wheelchair had been placed on another flight, he had to crawl off the plane at a regional destination (Paine, 2005).

\section{Customer Service}

Training for porters in transferring and assisting TwD was seen as essential by interviewees. Once a person had been placed on an aisle chair, it was ideal to board and seat them in as short a time as possible for a range of customer-service and intrapersonal reasons. Porters need to be available to assist when needed, well versed in transfer techniques and comfortable in working with TwD. Table 1 Quote 8 revealed that the interviewee's experience was spoiled by a series of customer service indiscretions where, 'I found the airline was really quite rude, in that (wife's name withheld) and I went to get on the plane and he yelled down the corridor, "I've got a couple of carry-ons here" ... That whole bad attitude to the customers' rights [to being treated with dignity] ....' (Interviewee). These experiences are directly related to the daily management practice at airports. Even after staff have undergone disability awareness training, major oversights can occur, particularly if porter numbers are down. Many TwD related experiences of being left on the plane for a prolonged period before disembarking. The 
Table 2

Phase of the Air Travel Chain, Practices and Resultant Essence of Experience

\begin{tabular}{|c|c|c|}
\hline Phase of the Travel Chain & Practice & $\begin{array}{l}\text { Essence of Experience From Embodiment to } \\
\text { (DIS)embodiment }\end{array}$ \\
\hline Pretravel Planning & $\begin{array}{l}\text { Segregated booking procedure } \\
\text { Inaccessible information formats } \\
\text { Independent travel criteria enforced in ad hoc fashion } \\
\text { Restriction of equipment/assistance animals per aircraft }\end{array}$ & $\begin{array}{l}\text { Inequity } \\
\text { Dependency } \\
\text { Loss of independence; extra cost } \\
\text { Separation from support; extra cost; extra time }\end{array}$ \\
\hline Boarding and disembarking & $\begin{array}{l}\text { Separated from equipment } \\
\text { Lack of privacy } \\
\text { Process of transfer } \\
\text { Service attitude } \\
\text { First on - last off: Length of process }\end{array}$ & $\begin{array}{l}\text { Loss of dignity } \\
\text { Loss of dignity and confidence } \\
\text { Loss of dignity } \\
\text { Dehumanising; devalued } \\
\text { Inequity; Fatigue }\end{array}$ \\
\hline Seat allocation & $\begin{array}{l}\text { Position of seats } \\
\text { Seats with arms that do not raise } \\
\text { Safety procedures }\end{array}$ & $\begin{array}{l}\text { Loss of dignity } \\
\text { Worry due to possible injury } \\
\text { Raised anxiety }\end{array}$ \\
\hline Personal care issues & $\begin{array}{l}\text { No or restricted access to onboard toilets } \\
\text { No onboard chair }\end{array}$ & $\begin{array}{l}\text { Health implications; dignity } \\
\text { dependence }\end{array}$ \\
\hline Equipment handling & $\begin{array}{l}\text { Inconsistent approaches to equipment procedures } \\
\text { Damage } \\
\text { Loss of equipment }\end{array}$ & $\begin{array}{l}\text { Trepidation with expectation } \\
\text { Helplessness } \\
\text { Devastation }\end{array}$ \\
\hline Customer service & $\begin{array}{l}\text { Inappropriate language } \\
\text { Poorly trained } \\
\text { Lack of staff rostered on } \\
\text { Reduced level of service }\end{array}$ & $\begin{array}{l}\text { Devalued } \\
\text { Fear; injury } \\
\text { Anxiety; health implications } \\
\text { Anxiety; health implications }\end{array}$ \\
\hline
\end{tabular}

delays of up to three hours were caused by a breakdown of communication about TwD being on the flight and the lack of available porters to disembark passengers. These delays created further complications with missed connecting flights and ground transport. However, as Table 1 Quote 9 suggests, there has been a much improved customer service practice, at least on some airlines, that has been the most appreciated by the individual.

\section{Discussion: (Dis)Embodied Experiences}

What emerged from the findings was that the discriminatory practices occurred across all stages of the air travel chain. These discriminatory practices have implications for both the socially constructed constraints faced by $\mathrm{TwD}$ as well as the resultant effects on the embodiment of the individuals and, hence, the essence of their experiences. The findings showed that there were a series of airline practices that created a new (DIS)embodiment as outlined in Table 2 . The discriminatory practices separated the individual from their embodied state to a newly (DIS)embodied existence. What emerged was essentially different to the previously discussed studies of embodiment, which have focused on enhancing the other sensory elements (sight, sound, tactility and taste) within tourism (Pritchard et al., 2007; Richards et al., 2010; Small et al., 2012).

By transforming TwD's independent, dignified and equitable embodied experience of everyday living in their place of residence, the transitory nature of the air travel chain stages experience was inequitable, dependent and undignified. The combination of these underlying values created a discontinuous air travel chain that led to the (DIS)embodiment of the TwD. As outlined in Figure 1, for wheelchair users their embodiment consists of four constituent parts: their impaired body and their management of their impairment; assistive aids and technology; an enabling physical environment and inclusive customer ser- vice attitudes. When any one or all of these are disrupted by the discontinuous nature of the air travel chain as described in the findings, the individual is cast back into a newly (DIS)embodied 'nature of being', where their independence, dignity and equitable means of citizenship are removed by the air travel chain's practices, procedures or attitudes.

As outlined in Table 2, the discriminatory practices have a significant impact on the individual beyond the structural elements across the air travel chain. These practices transform the person's impairment to one of a disability and thus constrain the citizenship of the individuals involved (Oliver, 1996). In the same way that Tregaskis (2003) describes the practices of leisure managers as disabling, the airline practices, procedures and personnel identified in the findings have the same effect - a disabling one - but by the nature of the air travel chain one that also (DIS) embodied the individual. As Papadimitriou (2008) established, PwD develop approaches to enable their embodied existence through interactions with an enabling environment, assistive technology and service attitudes in their everyday living. However, when faced with discriminatory practices and the discontinuous nature of the air travel chain, rather than being enwheeled (Papadimitriou 2008) they were (DIS)embodied. As the young man distressingly, yet eloquently, described the humiliation he felt when his forced immobility through a prolonged placement on a 'aisle chair' meant that he was unable to propel himself as he could in his manual wheelchair, navigate his way to the accessible toilet and take care of his toileting needs in an independent and dignified manner.

For some of the individuals involved, they are at least able to reclaim their dignity by challenging the practices that disabled the environments in which they were interacting, the service attitudes that were hostile towards them and, most importantly, the practices that took away their empowered embodiment. The Disability Discrimination Act 


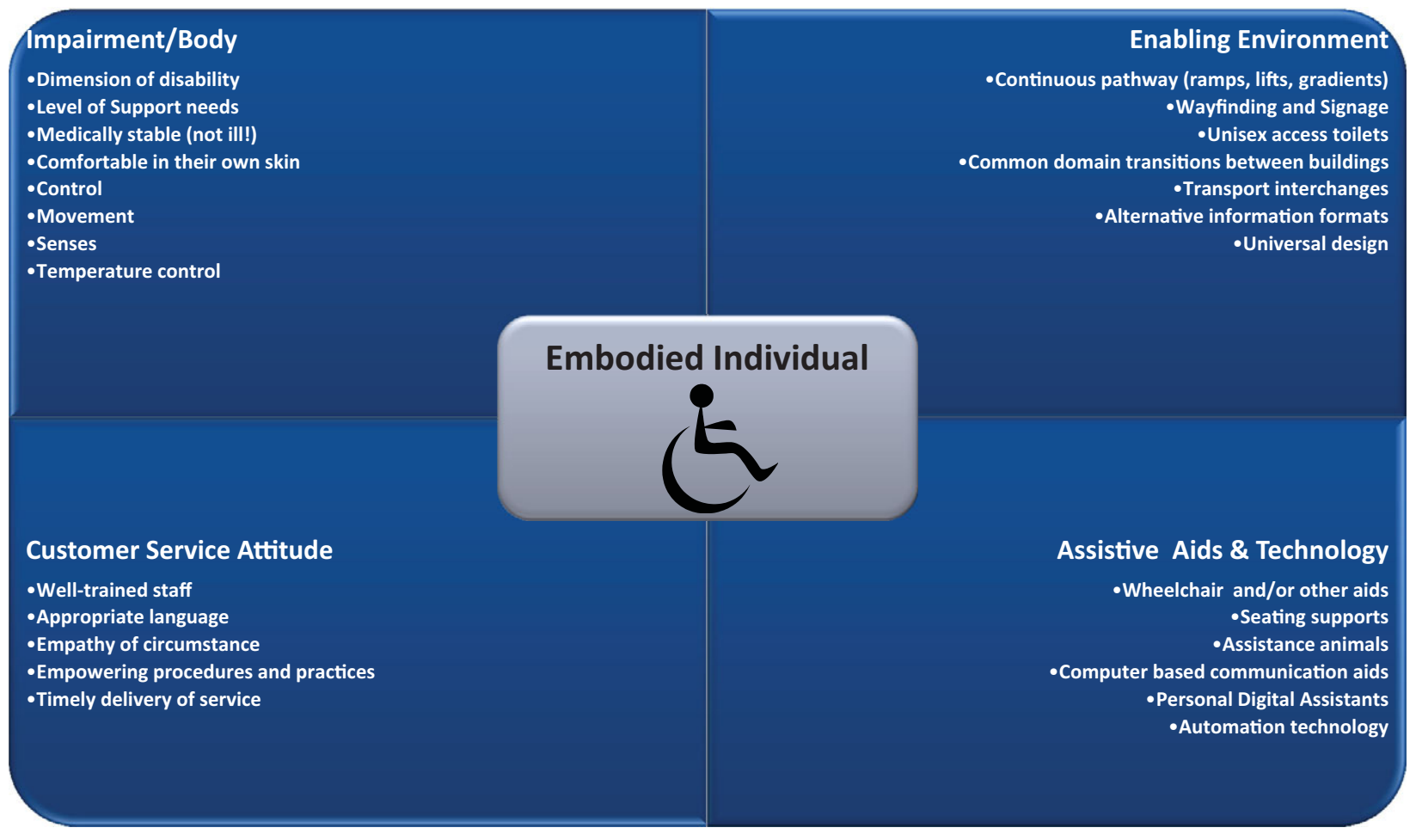

Figure 1

Examples of the constituent components of embodiment.

1992 (Cwlth) has provided an avenue through which to reclaim their independence for future air travel experiences by getting an acknowledgment that what occurred was discriminatory, inappropriate and not to be perpetuated in the future. The constraints experienced are structural, socially constructed and perpetrated by the practices, procedures and attitudes of the airlines, rather than a product their impairments. The essence of their experiences is a direct outcome of the discontinuous air travel chain. This insight provides an opportunity to learn from the inaccessible environments, practices and procedures identified, to understand the effect on their experiences across the air travel chain. The nature of their embodied experiences offers the air travel industry a way to transform their practices to enable and empower TwD in the future.

\section{Conclusion}

This article came about through the global reporting of problems associated with air travel and PwD, which highlighted a significant social phenomenon. The article identified practices that contravened discrimination legislation and the CRPWD. This finding is evidence that the air travel chain experiences of TwD had significant, ongoing and systematic structural access issues, practices, procedures and service attitudes. While the findings support social model understandings that the citizenship of TwD was significantly constrained, this in itself does not provide a full understanding of the effects of these practices on the embodiment of TwD and the resultant 'essence' of their experiences. The findings and discussion identified that the theoretical framework of the social model can be more powerful through the incorporation of an embodied understanding of the outcome of the practices on the nature of being. When discriminatory practices occur, the discontinuous nature of the air travel chain newly (DIS) embodied the TwD resulting in heightened anxiety, dependence, indignity and humiliation for the duration of the air travel chain experience.

An embodied understanding provides an opportunity for transformative industry practices. The practices that created a discontinuous air travel chain contravened the spirit and intent of the CRPWD. The procedures unnecessarily created exclusionary rather than transformative enabling practices that focus on the abilities of the individuals involved. The airline industry could reduce the negative experiences through improved management practices based on a greater embodied understanding to promote equitable, accessible, dignified and independent embodied experiences. Such management practices would not contravene essential international safety regulations but would require an organisational commitment to an embodied understanding. Travel is an essential component of the CRPWD, of which nondiscriminatory practice, accessibility, independence, dignity and equity are guiding principles with which airlines must engage for legal reasons but, more importantly, for service-related outcomes in an increasingly competitive air travel market.

\section{Acknowledgment}

This article was originally presented at the following conference and has been subsequently improved through presentation feedback, further theoretical development, 
analysis and discussion: Darcy, S. (2007, 19-23 June). Flying with Impairments: Improving Airline Practices by Understanding the Experiences of People with Disabilities. Paper presented at the Beating the Odds with Tourism Research! Las Vegas, Nevada. The author would also like to thank the reviewers of the article for their constructive criticism.

\section{References}

Australian Human Rights Commission. (2006). Disability Discrimination Act Complaints Cases Register and decisions. Retrieved from http://www. hreoc.gov.au/disability_rights/decisions/decisions.html

Barnes, C., \& Mercer, G. (2010). Exploring disability: A sociological introduction (2nd ed.). London: Polity.

Bohman, J. (2005). Critical theory. Stamford encyclopaedia of philosophy [Online]. Retrieved from http://plato.stanford.edu/entries/critical-theory/

Buhalis, D., \& Darcy, S. (Eds.). (2011). Accessible tourism: Concepts and issues. Bristol, UK: Channel View Publications.

Cole, S., \& Morgan, N. (2010). Introduction. In S. Cole \& N. Morgan (Eds.), Tourism and inequality: Problems and prospects (pp. $\mathrm{xv}-\mathrm{xxiii}$ ). Wallingford, UK: CABI.

Daniels, M.J., Drogin Rodgers, E.B., \& Wiggins, B.P. (2005). 'Travel Tales': An interpretive analysis of constraints and negotiations to pleasure travel as experienced by persons with physical disabilities. Tourism Management, 26(6), 919-930.

Darcy, S. (1998). Anxiety to access: Tourism patterns and experiences of New South Wales people with a physical disability. Sydney, Australia: Tourism New South Wales.

Darcy, S. (2002). Marginalised participation: Physical disability, high support needs and tourism. Fournal of Hospitality and Tourism Management, 9(1), 61-72.

Darcy, S. (2004). Disabling yourneys: The social relations of tourism for people with impairments in Australia - An analysis of government tourism authorities and accommodation sector practices and discourses (Unpublished doctoral dissertation). University of Technology, Sydney, Australia. Retrieved from http://epress.lib.uts.edu.au/dspace/handle/2100/260

Darcy, S. (2010). Inherent complexity: Disability, accessible tourism and accommodation information preferences. Tourism Management, 31(6), $816-826$.

Darcy, S., \& Taylor, T. (2009). Disability citizenship: An Australian human rights analysis of the cultural industries. Leisure Studies, 28(4), 419441 .

Daruwalla, P.S., \& Darcy, S. (2005). Personal and societal attitudes to disability. Annals of Tourism Research, 32(3), 549-570.

Doganis, R. (2005). The airline business. Abingdon, UK: Routledge.

European Disability Forum. (2011, 15 April). Clear violation of eu regulation leads to discrimination of passengers with disabilities Retrieved from http://www.edf-feph.org/Page_Generale.asp?DocID=13855\&thebloc $=$ 27020

Fullagar, S. (2011). Travelling with and beyond depression: Women's naratives of recovery and identity. In D. Buhalis \& S. Darcy (Eds.), Accessible tourism: Concepts and issues (pp. 123-137). Bristol, UK: Channel View Publications.

Glaser, B.G., \& Strauss, A.L. (1967). The discovery of grounded theory: Strategies for qualitative research. Chicago, IL: Aldine.

Holstein, J.A., \& Gubrium, J.F. (1994). Phenomenology, ethnomethodology, and interpretive practice. In N.K. Denzin \& Y.S. Lincoln (Eds.), Handbook of Qualitative Research (pp. 262-272). Thousand Oaks, CA: Sage.

Kayess, R., \& French, P. (2008). Out of darkness into light? Introducing the convention on the rights of persons with fisabilities. Human Rights Law Review, 8(1), 1-34. doi: 10.1093/hrlr/ngm044

Leiper, N. (2003). Tourism management (3rd ed.). Sydney, Australia: Hospitality Press.

McKercher, B., Packer, T., Yau, M., \& Lam, P. (2003). Travel agents as facilitators or inhibitors of travel: Perceptions of people with disabilities. Tourism Management, 24(4), 465-474.
Oliver, M. (1996). Understanding disability: From theory to practice. Basingstoke, UK: Macmillan.

Osborne, P. (2000). Travelling light: Photography, travel and visual culture: Manchester, UK:Manchester Univ Pr.

Packer, T.L., McKercher, B., \& Yau, M. (2007). Understanding the complex interplay between tourism, disability and environmental contexts. Disability \& Rehabilitation, 29(4), 281-292.

Paine, M. (2005, January 31). Disabled air trip hassles outlined. Hobart Mercury. Retrieved from http://www.themercury.com.au

Papadimitriou, C. (2008). Becoming en-wheeled: The situated accomplishment of re-embodiment as a wheelchair user after spinal cord injury. Disability \& Society, 23(7), 691-704.

Pelly, M. (2006, 2 June). Virgin backs down in disability row. Sydney Morning Herald, p. 3.

Pritchard, A., Morgan, N., Ateljevic, I., \& Harris, C. (Eds.) (2007). Tourism and gender: Embodiment, sensuality and experience. Wallingford, Oxfordshire UK: CABI Publishing.

Public Interest Advocacy Centre. (2007). Flight closed: Report on the experiences of people with disabilities in domestic airline travel in Australia. Sydney, Australia: Public Interest Advocacy Centre.

Richards, V., Pritchard, A., \& Morgan, N. (2010). (Re)Envisioning tourism and visual impairment. Annals of Tourism Research, 37(4), 1097-1116. doi: 10.1016/j.annals.2010.04.011

Rous, M., \& Ward, E. (1997). Anyone can travel: The essential travel guide for Seniors, the disabled, people with health problems and the regular traveller. Montreal, Quebec: Health Ideas.

Shakespeare, T., \& Watson, N. (2001). The social model of disability: An outdated ideology? In S.N. Barnartt \& B. Mandell Altman (Eds.), Exploring theories and expanding methodologies (Vol. 2, pp. 9-28). Stamford, CT: JAI Press.

Shaw, G., \& Coles, T. (2004). Disability, holiday making and the tourism industry in the UK: A preiminary survey. Tourism Management, 25, 397403.

Small, J., \& Darcy, S. (2011). Understanding tourist experience through embodiment: The contribution of critical tourism and disability studies. In D. Buhalis \& S. Darcy (Eds.), Accessible tourism: Concepts and issues (pp. 72-96). Bristol, UK: Channel View Publications.

Small, J., Darcy, S., \& Packer, T. (2012). The embodied tourist experiences of people with vision impairment: Management implications beyond the visual gaze. Tourism Management, 33(4), 941-950. doi: 10.1016/j.tourman.2011.09.015

Small, J.J., Harris, C., \& McIntosh, A. (2008). Whose body is welcome in paradise? In R. Richardson, L. Fredline, A. Patiar, \& M. Ternel (Eds.), Proceedings of the 18th Annual Council for the Australian University Tourism and Hospitality Education, Annual Council for Australian University Tourism :'Where the 'bloody hell' are we?' (pp. 1-18). Gold Coast, Australia: CAUTHE and Griffith University, Queensland.

Swain, J., Finkelstein, V., French, S., \& Oliver, M. (2004). Disabling barriers: Enabling environments (3rd ed.). London: Sage.

The Dominion Post. (2011, April 13). 'Humiliated': Jetstar slammed over refusing to fly disabled passengers, Sydney Morning Herald. Retrieved from http://www.smh.com.au/travel/travel-news/humiliatedjetstar-slammed-over-refusing-to-fly-disabled-passengers-20110413$1 \mathrm{ddm} 0 . \mathrm{html}$

Thomas, C. (2004). Disability and impairment. In J. Swain, S. French, C. Barnes, \& C. Thomas (Eds.), Disabling barriers: Enabling environments (pp. 21-28). London: Sage.

Tregaskis, C. (2003). Towards inclusive practice: An insider perspective on leisure provision for disabled people. Managing Leisure, 8(1), 2840.

Turco, D.M., Stumbo, N., \& Garncarz, J. (1998). Tourism constraints: People with disabilities. Parks and Recreation fournal, 33(9), 7884.

United Kingdom Department of Transport. (2003). Access to Air Travel for Disabled People: Code of Practice Retrieved from http://www.dft.gov. uk/stellent/groups/dft_mobility/documents/page/dft_mobility_507855. pdf. 
United Nations. (2006). Convention on the rights of persons with disabilities. New York: Author. Retrieved from http://www.un.org/esa/ socdev/enable/rights/convtexte.htm

U.S. Department of Transportation. (2009). Air Carrier Access Act of 1986 as amended (effective May 13, 2009). Washington: Author.

Waitt, G., \& Markwell, K. (2006). Gay tourism: Culture and context: Binghamton, NY: The Haworth Press.
Wilson, E., Harris, C., \& Small, J. (2008). Furthering critical approaches in tourism and hospitality studies: perspectives from Australia and New Zealand. Fournal of Hospitality and Tourism Management, 15(14), 15-18.

World Health Organization. (2001). International classification of functioning, disability and health (ICIDH-2). Geneva: Author.

World Health Organization, \& World Bank. (2011). World Report on Disability. Retrieved from http://www.who.int/disabilities/world_ report/2011/report/en/index.html 